\title{
New guidelines for the treatment of seasonal allergic rhinitis
}

\author{
Andrzej Emeryk ${ }^{1,2}$, Justyna Emeryk-Maksymiuk³, Kamil Janeczek² \\ ${ }^{1}$ Department of Paediatric Nursing, Medical University of Lublin, Lublin, Poland \\ ${ }^{2}$ Department of Paediatric Pulmonology and Rheumatology, Medical University of Lublin, Lublin, Poland \\ ${ }^{3}$ Department of Internal Medicine in Nursing, Medical University of Lublin, Lublin, Poland
}

Adv Dermatol Allergol 2019; XXXVI (3): 255-260

DOI: https://doi.org/10.5114/ada.2018.75749

\begin{abstract}
The paper discusses the classification and forms of allergic rhinitis with a special focus on seasonal allergic rhinitis (SAR). The general principles of SAR management are presented, including the role of nasal glucocorticoids, nasal and oral antihistamines, and antileukotrienes. Based on the latest guidelines, the current rules for the selection of drugs in the therapy of SAR are given, paying special attention to the initial treatment. The aim of the paper is to present updated guidelines for the pharmacological management of patients with seasonal allergic rhinitis.
\end{abstract}

Key words: seasonal allergic rhinitis, children, adults, antihistamines, nasal glucocorticoids, antileukotrienes.

\section{Definition and forms of allergic rhinitis}

Allergic rhinitis (AR) is an inflammatory process of the nasal mucosa, typically IgE-mediated, elicited by environmental allergens and characterized by the presence of inflammatory cells within the mucosa and submucosa [1]. The course of the disease involves one or more of the symptoms enumerated below, persisting for at least one hour a day for at least two consecutive days, which are reversible spontaneously or with treatment. The symptoms include nasal discharge, nasal itching, sneezing and nasal obstruction [2, 3].

The disease is a serious public health problem in a number of countries, including Poland where approximately 9 million people are affected by various forms of AR [4]. Allergic rhinitis has a profound negative impact on the quality of life of patients and their families (in the case of children with AR). It is also a major cause of school and work absenteeism [5-7]. Consequently, it is vital to ensure timely and correct diagnosis, and implement appropriate management based on the latest international or national guidelines.

For many years there have been attempts to systematize various forms of AR based on a number of criteria. The current classifications of AR take into account the following criteria:

1) allergen causing symptoms (aetiological classification; the oldest and still useful in the clinical setting, popular particularly in the USA),
2) duration of symptoms (clinical classification easy to implement in practice, with significant implications for therapy),

3) severity of clinical symptoms reported by the patient, including AR-related quality of life (clinical classification easy to implement in clinical practice, easily understandable to patients, with significant implications for therapy),

4) disease pathophysiology (pathophysiological classification with, as yet, limited use in clinical practice).

According to the first criterion, partially including the aetiology of the disease, AR is divided into seasonal (SAR), perennial (PAR) and episodic (EAR) types [8]. Seasonal allergic rhinitis (SAR) develops only during specific periods of the year (corresponding to the pollination of wind-pollinated plants or mould sporulation). Perennial allergic rhinitis (PAR) occurs when the condition is triggered by allergens found in the patient's environment at concentrations sufficient to induce symptoms of the disease all year round. The triggers include house dust mites, pet fur, cockroaches and mould in the Central Europe or wind-pollinated plant pollen in the tropical zone. Episodic allergic rhinitis (EAR) is caused by exposure to a specific airborne allergen on a sporadic and short-term basis [9].

Based on the second criterion, i.e. duration, $A R$ is classified [10] into intermittent (INT) and persistent (PER) types (Figure 1). Intermittent allergic rhinitis is defined by

Address for correspondence: Andrzej Emeryk, PhD, MD, Department of Paediatric Pulmonology and Rheumatology, Medical University of Lublin, 6 prof. A. Gębali St, 20-093 Lublin, Poland, e-mail: emerykandrzej@gmail.com

Received: 5.03.2018, accepted: 16.03.2018. 


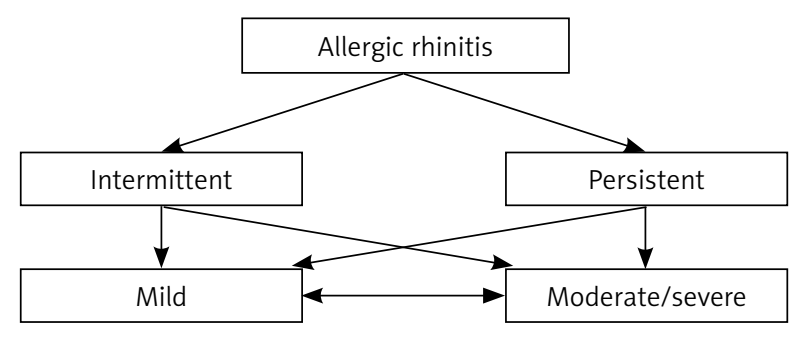

Figure 1. Classification of $A R$ and relationships between different AR forms

symptom duration of less than 4 days per week or less than a month per year, and PER allergic rhinitis refers to the presence of symptoms for $\geq 4$ days per week and $\geq 1$ month per year.

According to the third criterion, AR is classified as either mild or moderate/severe (original ARIA classification, oARIA), depending on the impact of the disease on the following quality-of-life measures [3] (Figure 1): a) daily activities and sport, b) school/work attendance, c) sleep, and d) need of therapy, as reported by the patient.

In mild AR, there is no impact on the quality-of-life aspects listed above. In moderate/severe AR, an adverse effect on one or more of the above items is present. On account of the high heterogeneity observed in the group of patients with this form of the disease, a more detailed classification has been proposed, consisting of three levels of AR severity [11]: mild, moderate and severe. In contrast to OARIA, the revised system is referred to as modified ARIA (mARIA) classification. The mild form is defined in the same manner as in OARIA. In the moderate form, the disease affects the presence of one, two or three out of four ( $a, b, c, d)$ of the above-mentioned elements of AR severity assessment. In the severe form, impact of the disease is seen in all four elements.
Based on the fourth criterion listed above, i.e. pathophysiology, AR is divided into IgE-mediated and nonIgE-mediated types. The former is much more common (>90\% cases), and the latter probably involves IgG antibodies, T lymphocytes and/or eosinophils [12]. Muraro et al. have recently proposed a new classification of IgEmediated AR endotypes [13]. However, its implementation in daily practice is still in its early stages (patients require detailed immunological assessment), just like the potential variation in therapy resulting from the classification.

Both intermittent (INT) and persistent (PER) AR may have a mild or moderate/severe clinical course and different forms of the disease may pass into one another (effect of evolution of the disease and/or therapy) (Figure 1). Some patients are affected by the so-called mixed rhinitis in which AR coexists with non-allergic rhinitis (44-87\% of patients with AR) [14].

Seasonal AR may have an intermittent course, for example in Poland some patients are only allergic to alder pollen. It may also take a persistent form as in patients with grass pollen allergy (Table 1).

\section{Seasonal allergic rhinitis and main disease-triggering allergens}

A few years ago, the results of the ECAP study investigating SAR prevalence in children and adults in Poland were published $[4,15]$. Table 2 lists data on the prevalence of SAR in selected Polish cities based on medical diagnosis of the disease [4].

The prevalence of SAR varied from $6.1 \%$ to $20.8 \%$ in the group of younger children, from $7.6 \%$ to $29.0 \%$ in the group of older children and from $8.8 \%$ to $28.9 \%$ in adults. The disease was more prevalent in boys/men than in girls/women. The data show that the condition is the most common inflammatory respiratory disease.

The dominant allergens triggering SAR in Poland include, in order of frequency, pollen of grasses/cereals,

Table 1. Pollination periods of wind-pollinated plants in Poland (approximate data unified for the country as a whole; differences for the beginning and/or the end of the pollination period between climatic regions in Poland span about 3 to 4 weeks) [18]

\begin{tabular}{lccccc}
\hline Plants & Alder, hazel & Birch & Oak, beech, willow, ash, poplar & Grasses, cereals & Goosefoot, plantain, mugwort \\
\hline Month & I-III/Jan-Mar & IV-V/Apr-May & IV-V/Apr-May & V-VII/May-July & VII-IX/July-Sep \\
\hline
\end{tabular}

Table 2. Prevalence of seasonal AR in Poland (\% population) in children and adults based on medical diagnosis

\begin{tabular}{lccc}
\hline City & Children aged 6-7 years (\%) & Children aged 13-14 years (\%) & Adults aged 20-44 years (\%) \\
\hline Warsaw & 20.8 & 31.1 & 27.4 \\
\hline Krakow & 9.2 & 12.2 & 9.6 \\
\hline Wroclaw & 6.1 & 7.6 & 8.8 \\
\hline Poznan & 17.0 & 29.0 & 28.9 \\
\hline Gdansk & 15.3 & 22.8 & 16.8 \\
\hline Bialystok & 10.7 & 15.5 & 12.5 \\
\hline
\end{tabular}


birch, mugwort, alder and hazel, followed by other pollens (nettle, goosefoot, broadleaf plantain and ragweed). The sequence in which different airborne pollens occur in Poland is quite characteristic [16]. The plant pollination season usually begins in the first decade of February, when hazel and alder pollen is detected in the air. In favourable weather conditions, however, the two plant pollen allergens are already airborne in mid-January. Birch, whose antigens are the most common cause of AR in the spring, begins pollinating in April. Other deciduous trees including ash, beech, hornbeam and poplar, usually produce pollen in Poland until mid-May, and are less clinically significant than birch. Exposure to grass pollen antigens, which are the most common cause of SAR in Poland, is the greatest at the end of May, in June and July. In August and September, the main airborne pollens are herbaceous plants (weeds), primarily mugwort, goosefoot and plantain. Allergy to mugwort pollen allergens is the third most common (after grass and birch pollen) cause of SAR, and the allergens appear in August and September. The above data are listed in Table 1 [17].

It must be noted that SAR symptoms very commonly (in $60-90 \%$ of cases) coexist with symptoms of allergic conjunctivitis such as burning and itching of the eyes, redness and increased lacrimation. The condition is referred to as allergic rhinoconjunctivitis.

\section{Rules of seasonal allergic rhinitis management: drug categories}

For many years, the algorithm for the treatment of patients with SAR has combined four basic modalities which often require concurrent application [3, 18-20]:
1) education of patients (in children also their caregivers), 2) avoidance of allergens and irritants (possible in SAR),

3) pharmacotherapy (all therapeutic options),

4) allergen immunotherapy (sublingual or subcutaneous, effective particularly in SAR).

Seasonal allergic rhinitis pharmacotherapy is based on different drug categories, either used in monotherapy or, in some patients, in combined regimens according to the criteria included in currently valid diagnostic and therapeutic consensus recommendations. The most important drug categories include:

- glucocorticoids (GC): intranasal - GCin, oral - GCpo,

- H1 receptor antagonists (second-generation H1-antihistamines - AH) (oral - AHpo, intranasal - AHin),

- antileukotrienes (ALTR) (in children mainly montelukast),

- ipratropium bromide (intranasal),

- $\alpha$-sympathomimetics (intranasal, oral),

- saline solutions (intranasal),

- anti-IgE antibodies (subcutaneous),

- cromones (intranasal).

The effect of different drug categories on symptoms of SAR and ocular manifestations frequently accompanying the disease varies greatly, as shown in Table 3 [3, 8, 21-25].

\section{Current principles of drug selection in seasonal allergic rhinitis}

The selection of pharmacological options suitable for a particular patient depends to the largest extent on the form and clinical severity of SAR, patient's age (approved drug indications), drug availability on the market, price, and patient acceptance and satisfaction with a particular management modality $[8,26,27]$. The pharmacother-

Table 3. Drug categories used in the therapy of SAR and their effect on nasal and ocular symptoms under normal exposure

\begin{tabular}{|c|c|c|c|c|c|c|}
\hline \multirow[t]{2}{*}{ Drug category } & \multicolumn{6}{|c|}{ SAR symptoms and ocular symptoms } \\
\hline & Sneezing & Itching & $\begin{array}{c}\text { Watery } \\
\text { discharge }\end{array}$ & $\begin{array}{c}\text { Nasal } \\
\text { blockage }\end{array}$ & $\begin{array}{c}\text { Smell } \\
\text { disorders }\end{array}$ & $\begin{array}{c}\text { Ocular } \\
\text { symptoms }\end{array}$ \\
\hline Antihistamines (p.o.) & ++ & ++ & ++ & $+/-$ & - & ++ \\
\hline Antihistamines (i.n.) & ++ & +++ & ++ & + & - & - \\
\hline Ipratropium bromide (i.n.) & - & - & +++ & - & - & - \\
\hline$\alpha$-sympathomimetics (i.n.) & - & - & - & ++ & $+/-$ & - \\
\hline$\alpha$-sympathomimetics (p.o.) & - & - & - & + & - & $+/-$ \\
\hline Antileukotrienes (p.o.) & + & + & ++ & ++ & + & + \\
\hline Glucocorticoids (i.n.) & +++ & +++ & +++ & ++ & + & ++ \\
\hline Glucocorticoids (p.o.) & +++ & ++ & +++ & ++ & + & +++ \\
\hline Anti-lgE (s.c.) & ++ & ++ & ++ & ++ & nd & ++ \\
\hline Saline solutions (i.n.) & + & + & + & nd & - & - \\
\hline Cromones (i.n.) & + & + & + & $+/-$ & - & - \\
\hline
\end{tabular}


apy of SAR is gradable. If the disease exacerbates, the treatment can be intensified, usually by adding another medication (step-up approach). Conversely, if there is an improvement in symptom control, the therapy is reduced, typically by discontinuing 1 or 2 drugs (step-down approach) [27].

In 2015, a study entitled "MACVIA-ARIA Sentinel Network for allergic rhinitis (MASK-rhinitis): The new generation guideline implementation" was published, providing a very important resource for patients [28]. The study proposes a mobile phone application, MACVIA-ARIA, which allows patients to easily keep track of a number of parameters in the Visual Analogue Scale (VAS), including general well-being, nasal symptoms, conjunctival (ocular) symptoms, asthma symptoms and impact of symptoms on work productivity. VAS is a 10-centimetre scale which can be used by the patient at home (or by the physician during the patient's visit) to mark the severity of symptoms (from zero - no symptoms, to 10 most severe symptoms). VAS is a sensitive and precise tool for the assessment of AR symptoms and correlates well with the patients' quality of life [29]. The scale is particularly useful in patients with SAR [30]. Objective recording of SAR symptoms makes it possible to select a more effective drug therapy and enables adjustments by the physician but also by the pharmacist and/or patients themselves [31, 32].

The current therapeutic algorithm for AR (including SAR) proposed in the MACVIA-ARIA guidelines for previously untreated (first-line) patients $\geq 12$ years of age recommends one of the following options [20]: AHpo or AHin, GCin, ALTR (montelukast) and combination therapy: GCin + AHin (azelastine).

In patients having AR symptoms with a VAS score of $<5$, the guidelines recommend selecting one drug from the options listed above (without specifying which one). The recommended management for patients with more severe symptoms (VAS $\geq 5$ ) is:

1) in patients with symptoms indicative of INT AR, the management is the same as in patients with $V A S<5$;

2 ) in patients with symptoms indicative of PER AR, the recommended therapy is GCin or GCin + azelastine.

Further therapy depends on the patient's response to the initial treatment (daily VAS score assessment and, if necessary, modification of management after 48-72 h).

In patients with AR previously treated with one of the four available therapeutic options (AHpo/AHin or GCin or ALTR (montelukast) or combination treatment with GCin + AHin (azelastine)) and a VAS score of $<5$, the recommended management is:

1) in cases of INT AR or absence of allergen exposure reduce the treatment (step-down approach) or discontinue the therapy;

2) in cases of PER AR or presence of allergen exposure maintain the treatment or intensify the therapy (stepup approach).
Further therapy depends on the patient's response to the initial treatment (daily VAS score assessment and, if necessary, modification of management after 48-72 h).

In patients with a current VAS score of $\geq 5$, regardless of AR type, the treatment should be stepped up by adding GCin or a combination of GCin + AHin (azelastine). Further therapy depends on the patient's response to the initial treatment (daily VAS score assessment and, if necessary, modification of management after 7 days). The current principles of patient management in AR (without differentiation into SAR and PER AR) have recently been summarized by Bousquet et al. [20]. The process of selecting a suitable therapeutic option should be guided by the following principles:

- AHpo or AHin are less effective than GCin for the control of all symptoms of allergic rhinitis.

- ALTR (montelukast) is usually considered less effective than AHpo.

- There are no differences in the assessed efficacy of AHin and AHpo, so no definite recommendations have yet been made.

- Combined intranasal fluticasone propionate (FP) and azelastine (AZL) in a single intranasal device is more clinically effective than monotherapy, and it is indicated for patients when monotherapy with either AHin or GCin is considered inadequate.

- AHin and GCin are similarly effective for the treatment of ocular symptoms. However, the combination of FP and AZL is more effective than FP alone.

- Most studies show that combinations of AHpo and GCin or ALTR (montelukast or another drug from this category) and GCin are not more effective than GCin in monotherapy.

- Intraocular AH or cromones are effective for the treatment of ocular symptoms caused by allergic conjunctivitis.

- GCin are clinically effective after a few days of treatment, whereas AHin or combined intranasal FP and AZL produce a much more rapid clinical effect.

- First-generation AH should not be used in AR.

- Further studies are necessary in preschool age children in order to develop strong therapeutic recommendations, however recent research has demonstrated the efficacy of AHpo.

As mentioned above, the management algorithms for SAR proposed to date have not provided clear recommendations for selecting a therapeutic option for the initial therapy out of the four modalities listed above, especially based on the recognized GRADE methodology (Grading of Recommendations, Assessment, Development and Evaluations) [33, 34]. The problem has recently been taken up by a team of the most prominent American experts, and conclusions of their GRADE-based study were published in December 2017 [35]. The authors of the study formulated three key questions having practical significance and pertaining to the initial patient 
management in moderate/severe SAR (in previously untreated patients):

1. Is there any clinical benefit of using a combination of an AHpo and a GCin compared with monotherapy with a GCin in patients who are $>12$ years of age?

2. How does montelukast compare with a GCin in terms of clinical efficacy in patients who are $\geq 15$ years of age?

3. Is there any clinical benefit of using combination therapy with a AHpo and a GCin compared with monotherapy with either drug in patients who are $>12$ years of age?

Three recommendations were formulated in response to the three questions.

\section{Recommendation 1}

For the initial treatment of moderate/severe SAR in patients aged 12 years or older, clinicians should routinely prescribe monotherapy with a GCin rather than a combination of a GCin and an AHpo (strength of recommendation: strong).

\section{Authors' own commentary}

The recommendation significantly changes the management guidelines recommended to date, in which the treatment with a GCin and an AHpo was regarded as a "gold standard" in the therapy of more severe SAR. However, the treatment based on the two drug types fails to produce clinically significant additional benefits over a GCin in monotherapy and it is more expensive than the latter. Furthermore, since the combination is not superior to a GCin, it will encourage the shift to a GCin in patients who show no clinical benefit from treatment with an AHpo alone (instead of adding a GCin to an AHpo).

\section{Recommendation 2}

For the initial treatment of moderate/severe SAR in patients aged 15 years or older, clinicians should prescribe monotherapy with a GCin over montelukast (strength of recommendation: strong).

\section{Authors' own commentary}

The recommendation only slightly changes the current SAR management guidelines. Montelukast has been known for many years to be a markedly weaker anti-inflammatory drug than GCin, which is stressed in the 2016 study by Bousqet et al. [20]. The role of montelukast in the therapy of SAR seems to have been decreasing markedly in recent years. In practical terms, the drug may be effective only in patients with SAR coexisting with asthma during the pollination season (which is consistent with the Polish SPC of the drug) [36]. Montelukast can also have applications in a small group of patients with SAR who are intolerant of intranasal drugs [37].

\section{Recommendation 3}

For the initial treatment of moderate/severe SAR in patients aged 12 years or older, clinicians may recommend the combination of a GCin and AHin (strength of recommendation: weak).

\section{Authors' own commentary}

Only one GCin and AHin combination is available in Poland. It is the product called Dymista ${ }^{\circledR}$ containing an original formulation of FP with AZL in a single intranasal device. According to the current SPC for the medicinal product, the combination is effective in relieving symptoms of moderate/severe SAR in cases when other AHin or GCin fail to ensure adequate control of disease symptoms [38]. Consequently, the combination seems more appropriate as a second-line therapeutic modality which can be introduced after attempting monotherapy. However, the current therapeutic algorithm for SAR proposed in the MACVIA-ARIA guidelines for patients aged $\geq 12$ years includes the AHin and GCin combination as one of the four proposed options of first-line therapy, as mentioned above [20]. Unfortunately, there are still no clear indications which groups of patients would benefit from this therapy as opposed to other therapeutic options in the initial treatment of SAR.

\section{Conclusions}

Seasonal allergic rhinitis is triggered by allergens of wind-pollinated plants (tree, grass/cereal and weed/bush pollen). In the initial treatment of moderate/severe SAR in previously untreated patients aged 12 years or older, clinicians should routinely prescribe monotherapy with an intranasal glucocorticoid instead of combined therapy with an intranasal glucocorticoid and an oral secondgeneration antihistamine (strong recommendation) or montelukast in monotherapy (strong recommendation). Another possibility is the combination of an intranasal glucocorticoid with an intranasal antihistamine drug in a single intranasal device (weak recommendation). The above recommendations reduce the role of oral antihistamine drugs and montelukast in this group of patients with SAR.

\section{Conflict of interest}

The authors declare no conflict of interest.

\section{References}

1. Khan DA. Allergic rhinitis and asthma: epidemiology and common pathophysiology. Allergy Asthma Proc 2014; 35: 357-61.

2. Cauwenberge P, Bachert C, Passlacqua $G$ et al. Consensus statement on the treatment of allergic rhinitis. Allergy 2000; 55: 116-34.

3. Bousquet J, Khaltaev N, Cruz AA, et al. Allergic Rhinitis and its Impact on Asthma (ARIA) 2008 Update (in collaboration with 
the World Health Organization, GA2LEN and AllerGen). Allergy 2008; 63 Suppl. 86: 8-160.

4. Samoliński B, Sybilski AJ, Raciborski F, et al. Prevalence of rhinitis in Polish population according to ECAP (Epidemiology of Allergic Disorders in Poland) study. Otolaryngol Pol 2009; 63: 324-30.

5. Devillier P, Bousquet J, Salvator H, et al. In allergic rhinitis, work, classroom and activity impairments are weakly related to other outcome measures. Clin Exp Allergy 2016; 46: 1456-64.

6. Zhou S, Hur K, Shen J, Wrobel B. Impact of sinonasal disease on depression, sleep duration, and productivity among adults in the United States. Laryngoscope Investig Otolaryngol 2017. 2: 288-94.

7. Hoehle LP, Speth MM, Phillips KM, et al. Association between symptoms of allergic rhinitis with decreased general healthrelated quality of life. Am J Rhinol Allergy 2017; 31: 235-9.

8. Wallace DV, Dykewicz MS, Bernstein DI, et al. The diagnosis and management of rhinitis: an updated practice parameter. J Allergy Clin Immunol 2008; 122 (2 suppl): S1-84.

9. Seidman MD, Gurgel RK, Lin SY, et al. Clinical practice guideline: allergic rhinitis executive summary. Otolaryngol Head Neck Surg 2015; 152: 197-206.

10. Bousquet J, van Cauwenberge P, Khaltaev N. Allergic rhinitis and its impact on asthma. J Allergy Clin Immunol 2001; 108 Suppl.: 147-334.

11. Valero A, Ferrer M, Sastre J, et al. A new criterion by which to discriminate between patients with moderate allergic rhinitis and patients with severe allergic rhinitis based on the allergic rhinitis and its impact on asthma severity items. J Allergy Clin Immunol 2007; 120: 359-65.

12. Johannson SGO, Hourihane JOB, Bousquet J, et al. A revised nomenclature for allergy. An EAACI position statement from the EAACI nomenclature task force. Allergy 2001; 56: 813-24.

13. Muraro A, Lemanske RF Jr, Hellings PW, et al. Precision medicine in patients with allergic diseases: airway diseases and atopic dermatitis-PRACTALL document of the European Academy of Allergy and Clinical Immunology and the American Academy of Allergy, Asthma \& Immunology. J Allergy Clin Immunol 2016; 137: 1347-58.

14. Settipane RA, Charnock DR. Epidemiology of rhinitis: allergic and nonallergic. Clin Allergy Immunol 2007; 19: 23-34.

15. Samoliński B. ECAP - Epidemiologia Chorób Alergicznych w Polsce. Raport z badań przeprowadzonych w latach 2006 2008 w oparciu o metodologię ECRHS II i ISAAC. Uniwersytet Medyczny w Warszawie, Warszawa 2008.

16. Rapiejko P, Lipiec A, Samoliński B. Podstawy etiopatogenezy alergicznego nieżytu nosa. In: Alergiczny nieżyt nosa u dzieci. Emeryk A (ed.). Termedia, Poznan 2010.

17. Rapiejko P. Sezon pylenia roślin w Polsce w 2016 roku. Alergia 2016; 3: 14-6.

18. http://www.alergen.info.pl/kalendarz_pylenia_roslin.php.Pobrano 10.01.2017 r.

19. Samoliński B, Arcimowicz M (eds). Polskie Standardy Leczenie Nieżytów Nosa (PoSLeNN). Stanowisko Panelu Ekspertów Polskiego Towarzystwa Alergologicznego. Alerg Pol 2013; Suppl 1: 17-167.

20. Bousquet J, Schünemann HJ, Hellings PW, et al. MACVIA clinical decision algorithm in adolescents and adults with allergic rhinitis. J Allergy Clin Immunol 2016; 138: 367-74.

21. Juel-Berg N, Darling P, Bolvig J, et al. Intranasal corticosteroids compared with oral antihistamines in allergic rhinitis: a systematic review and meta-analysis. Am J Rhinol Allergy 2017; 31: 19-28.

22. Gane J, Buckley R. Leukotriene receptor antagonists in allergic eye disease: a systematic review and meta-analysis. J Allergy Clin Immunol Pract 2013; 1: 65-74.
23. Wei $\mathrm{C}$. The efficacy and safety of $\mathrm{H} 1$-antihistamine versus montelukast for allergic rhinitis: a systematic review and meta-analysis. Biomed Pharmacother 2016; 83: 989-97.

24. Meltzer EO. Intranasal anticholinergic therapy of rhinorrhea. J Allergy Clin Immunol 1992; 90: 1055-64.

25. Tsabouri S, Tseretopoulou X, Priftis K, Ntzani EE. Omalizumab for the treatment of inadequately controlled allergic rhinitis: a systematic review and meta-analysis of randomized clinical trials. J Allergy Clin Immunol Pract 2014; 2: 332-40.

26. Meltzer EO. Pharmacotherapeutic strategies for allergic rhinitis: matching treatment to symptoms, disease progression, and associated conditions. Allergy Asthma Proc 2013; 34: 301-11.

27. Roberts $P$, Xatzipsalti $M$, Bornego $L M$, et al. Paediatric rhinitis: position paper of the European Academy of Allergology and Clinical Immunology. Allergy 2013; 68: 1102-16.

28. Bousquet J, Schunemann HJ, Fonseca J, et al. MACVIA-ARIA Sentinel Network for allergic rhinitis (MASK-rhinitis): the new generation guideline implementation. Allergy 2015; 70: 1372-92.

29. Klimek L, Bergmann KC, Biedermann T, et al. Visual analogue scales (VAS): measuring instruments for the documentation of symptoms and therapy monitoring in cases of allergic rhinitis in everyday health care: Position Paper of the German Society of Allergology (AeDA) and the German Society of Allergy and Clinical Immunology (DGAKI), ENT Section, in collaboration with the working group on Clinical Immunology, Allergology and Environmental Medicine of the German Society of Otorhinolaryngology, Head and Neck Surgery (DGHNOKHC). Allergo I Int 2017; 26: 16-24.

30. Rapiejko P. Elektroniczne kwestionariusze monitorujące objawy ułatwią diagnostykę i leczenie alergicznego nieżytu nosa. Alergoprofil 2016; 12: 153-9.

31. May JR, Dolen WK. Management of allergic rhinitis: a review for the community pharmacist. Clin Ther 2017; 39: 2410-9.

32. Carr WW, Yawn BP. Management of allergic rhinitis in the era of effective over-the-counter treatments. Postgrad Med 2017; 129: 572-80.

33. Brożek JL, Baena-Cagnani CE, Bonini S, et al. Methodology for development of the allergic rhinitis and its impact on asthma guideline 2008 update. Allergy 2008; 63: 38-46.

34. Terracciano L, Brozek J, Compalati E, Schunemann H. GRADE system: new paradigm. Curr Opin Allergy Clin Immuno 2010; 10: 377-83.

35. Dykewicz MS, Wallace DV, Baroody F, et al. Treatment of seasonal allergic rhinitis. An evidence-based focused 2017 guideline update. Practice Guideline. Ann Allergy Asthma Immunol 2017; 119: 489-511.

36. http://leki.urpl.gov.pl/files/20 Montelukast.pdf). Available at: 10.01.2018.

37. Hellings PW, Dobbels F, Denhaerynck K, et al. Explorative study on patient's perceived knowledge level, expectations, preferences and fear of side effects for treatment for allergic rhinitis. Clin Transl Allergy 2012; 2: 9.

38. https://www.leki-informacje.pl/sites/default/files/Charakterystyka-1281_B-30253-20151104000325.pdf. Available at: 10.01.2018. 